\title{
Prevalence of self-reported overweight-obesity and its association with socioeconomic and health factors among older Mexican adults
}

\author{
Liliana Ruiz-Arregui, M en C, (1) Lilia Castillo-Martínez, M en C,(1) Arturo Orea-Tejeda, MD, ${ }^{(1)}$ \\ Silvia Mejía-Arango, PhD, ${ }^{(1)}$ Alejandro Miguel-Jaimes, MD.(')
}

\author{
Ruiz-Arregui L, Castillo-Martínez L, Orea-Tejeda A, \\ Mejía-Arango S, Miguel-Jaimes A. \\ Prevalence of self-reported overweight-obesity \\ and its association with socioeconomic and \\ health factors among older Mexican adults. \\ Salud Publica Mex 2007;49 suppl 4:S482-S487.
}

\begin{abstract}
Objective: To investigate the prevalence of obesity and its association with socioeconomic factors and comorbidities in a population-based study. Material and Methods: Data were examined from 4605 persons ages 60 and older that participated in the 200I Mexican Health and Aging Study, conducted in rural and urban communities in Mexico. The prevalence of obesity (according to self-reported weight and height) was obtained, stratified by age, and logistic regression was used to study cross-sectional associations between obesity and socioeconomic factors. Results: Of the population studied, $20.9 \%$ were classified as obese and the prevalence diminishes with age. Overall, women were more likely than men to be obese. Lower educational level was associated with lower risk of overweight. In both men and women, obesity was more common between subjects with hypertension (OR I.38 and I.7I, respectively) and long-distance walk limitation (OR 2.08 and 2.2I, respectively). Conclusion. In older Mexican adults, hypertension and long-distance walk limitation were independent associated factors for higher prevalence of obesity.
\end{abstract}

Key words: obesity; elderly; socioeconomic factors; health factors; Mexico
Ruiz-Arregui L, Castillo-Martínez L, Orea-Tejeda A, Mejía-Arango S, Miguel-Jaimes A.

Prevalencia de sobrepeso-obesidad autorreportados y su asociación con factores socioeconómicos y de salud en población de edad avanzada en México.

Salud Publica Mex 2007;49 supl 4:S482-S487.

\section{Resumen}

Objetivo: Estudiar la prevalencia de obesidad y su asociación con factores socioeconómicos y comorbilidades. Material y métodos: Se analizaron los datos de 4605 personas de 60 años y más que participaron en el Estudio Nacional sobre Salud y Envejecimiento en México 200I (ENASEM 200I) en zonas rurales y urbanas. La prevalencia de obesidad (peso y talla autorreportados) se obtuvo estratificada por edad y mediante una regresión logística se asoció con factores socioeconómicos. Resultados: $20.9 \%$ se clasificaron como obesos y la prevalencia disminuyó con la edad. En general las mujeres tuvieron mayor probabilidad de ser obesas. Una baja escolaridad se asoció con menor riesgo de sobrepeso. En hombres y mujeres la obesidad se asoció con hipertensión (RM I.38 y I.7I respectivamente) y con dificultad para caminar (RM 2.08 y 2.21 respectivamente). Conclusión: En la población de edad avanzada en México la hipertensión y la dificultad para caminar varias cuadras se asoció con mayor prevalencia de obesidad.

Palabras clave: obesidad; anciano; factores socioeconómicos; salud; México

(I) Instituto Nacional de Ciencias Médicas y Nutrición Salvador Zubirán. Mexico.

Received on: September 25, 2005 • Accepted on: January 3I, 2007

Address reprint request to: M en C Lilia Castillo-Martínez. Instituto Nacional de Ciencias Médicas y Nutrición Salvador Zubirán.Vasco de Quiroga I5, Col. Sección XVI. 14000 Tlalpan, México DF, México.

E-mail:camlI225@hotmail.com 
$\mathrm{O}^{\mathrm{b}}$ besity is a serious public health problem that is becoming very common in developed and developing countries. Agreat number of persons become overweight or obese as they get older, which is associated with a decrease in physical activity and basal metabolism, and a body fat redistribution to the abdominal area. ${ }^{1}$

Several studies have found that the association between obesity and mortality is lower in elderly persons; however, morbidity increases with body mass index. ${ }^{2,3}$ Overweight and obesity are associated with medical conditions such as hypertension, type 2 diabetes mellitus, osteoarthritis, respiratory disease, ${ }^{4,5}$ and depression. ${ }^{6,7}$ They are also related with diminished functional status, principally because of mobility limitations. Decrease in physical activity causes de-conditioning and the risk of fragility. ${ }^{8}$

The association between obesity and cardiovascular disease has been reported in the adult population; however, there are few studies of elderly patients and the results are contradictory. ${ }^{9}$

In several surveys, tobacco and alcohol consumption have been found to be factors associated with a lower prevalence of obesity and overweight, mainly because of a decrease in intake and an increase in energy expenditure. $^{10}$

According to the National Center for Health Statistics, in 2000 the obesity rate for the U.S. population ages 65-74 years was 36.05\%. ${ }^{11}$ In 1997, in Canada the prevalence of overweight and obesity in people ages 65 and older were 43.3 and $20.9 \%$, respectively. ${ }^{12}$

In developing countries where overnutrition and undernutrition co-exist, the figures are also important. In Mexico, the 2000 National Health Survey showed that the prevalence of obesity and overweight increased from $21.5 \%$ in 1993 to $23.7 \%$ in 2000 . In people ages 60-79 years, $39 \%$ were overweight and $26 \%$ were obese. ${ }^{13}$

Several studies in both developed and developing countries show that in all age groups, overweight is more prevalent in men and obesity is more prevalent in women. An increase in overweight and obesity according to age can be observed, however between 60 and 65 years of age, the body mass index (BMI) began to decrease. ${ }^{14,15}$

Information about distribution of obesity between social classes in older populations is poor and results obtained in young and adult populations are contradictory. Several studies have confirmed an inverse association between obesity and socioeconomic level in adult women in developed countries; however, this association has not been observed in men and children. Studies in developing countries have found greater occurrences of obesity in higher socioeconomic classes. ${ }^{16}$
Few studies have evaluated overweight and obesity prevalence and its determinants, or their relation with morbidity and mortality in the elderly Latin American population. The aim of this study was to investigate the prevalence of obesity and its independent associations with socioeconomic factors and comorbidities such as hypertension, myocardial infarction and diabetes in a large population-based study.

\section{Material and Methods}

The 2001 Mexican Health and Aging Study (MHAS) database was analyzed. ${ }^{17}$ The MHAS is a cross-sectional, population-based study conducted in rural and urban communities in Mexico in 2001. Data from 7170 persons older than 60 years of age were included. From this, 4905 had self-reported weight and height which were verified by Avila-Funes (2004), who concluded that it is a valid method that can be used to accurately estimate height and weight in elderly Mexican people. ${ }^{18}$ Informed consent was obtained for all subjects according to the "Declaration of Helsinki on Ethical Principles for Medical Research Involving Human Subjects".

Based on self-reported weight and height, body mass index (BMI) was calculated by dividing total body weight (kilograms) by the squared standing height (square meter). Using this index, patients were grouped, according to the World Health Organization classification, ${ }^{19}$ into low body weight (BMI $\left.\leq 19.9\right)$, normal body weight (BMI 20 to 24.9), overweight (BMI 25 to 29.9) and obesity (BMI $\geq 30)$. From this analysis we excluded 300 (6.1\%) patients with low body weight $(\mathrm{BMI}<19.9)$.

The socio-demographic variables studied were: gender, age (5-year groupings), educational level (equal or less than primary vs. greater than primary), marital status (unmarried/separated/unmarried widower/ widow, married / cohabitation) and self-rated economic status (fair/poor vs. good/very good/excellent). Health variables included: functional limitation (problem with at least one activity of daily living [ADL]), long-distance walk limitation, self-rated health status (fair/poor vs. good/very good/excellent), and self-reported morbidity (depression, hypertension, diabetes, respiratory disease, myocardial infarction, stroke, arthritis and bowel disease). Current smoking status and alcohol use (abstainer [none], infrequent [ $<1$ drink per week]), moderate (1-20 drinks per week), and heavy (more than 20 drinks per week) were also included.

\section{Statistical Analysis}

Results are presented as percentages. For the proportion comparison among variables, Pearson $\mathrm{x}^{2}$ was used. 
Using stepwise logistic regression analyses, predictors of overweight and obesity relative to normal weight were examined. Analyses were stratified by gender. A $p$ value $<0.05$ was considered significant. The SPSS Inc. (Version 10.0) statistical program was used for the statistical analysis.

\section{Results}

Out of 4605 persons studied, 2392 (51.9\%) were men and $2213(48.1 \%)$ were women. Normal weight was present in $35.8 \%$, overweight in $43.3 \%$, and obesity in $20.9 \%$ of the total population studied. Figure 1 shows the distribution of normal weight, overweight and obesity among men and women stratified by age and gender. Women were more likely to be obese compared to men (24.8vs. $17.3 \%$ ). In both men and women, prevalence of overweight and obesity were low in the oldest age groups.

All socioeconomic and health variables included in this study have significant differences when compared by gender, with the exception of age, education level, respiratory disease, stroke and current smokers.

Table I shows demographic and socioeconomic characteristics stratified by gender in subjects with normal weight, overweight and obesity. There is a statistically significant lower occurrence of single men classified as overweight and obese compared with normal weight. People with a low educational level have a
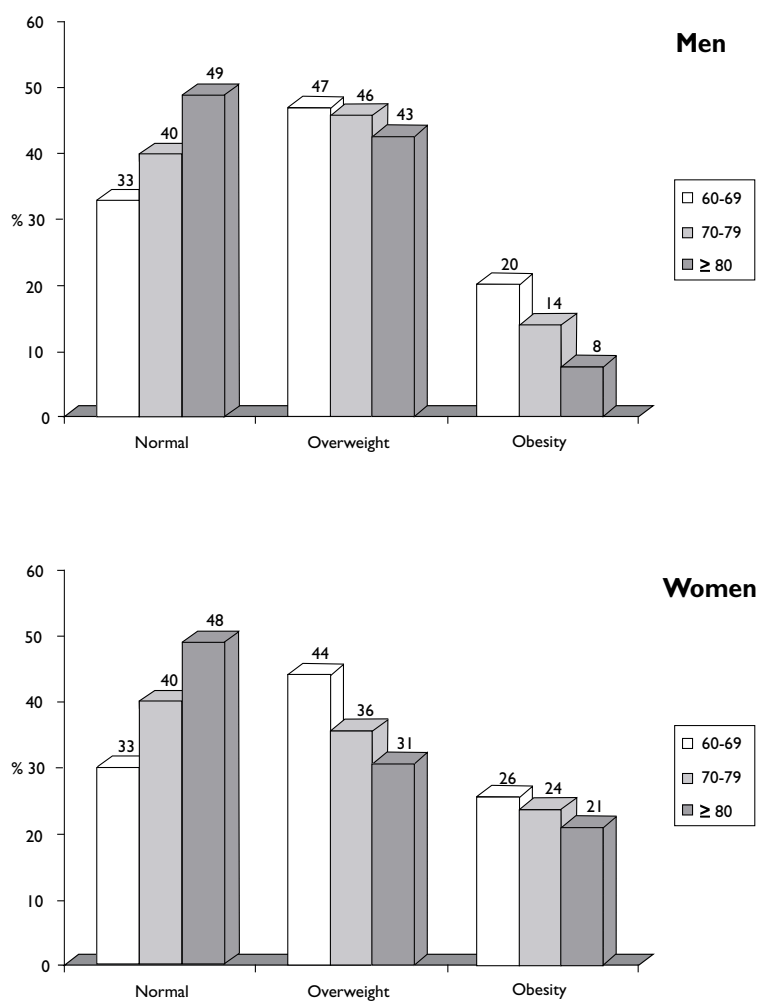

Figure I. Prevalence of normal weight, overweight AND OBESITY BY AGE AND GENDER

Table I

SOCIODEMOGRAPHIC CHARACTERISTICS IN THE OVERWEIGHT AND OBESE POPULATIONS COMPARED WITH THE NORMAL population. Mexican Health and Aging Study 200I*

\begin{tabular}{|c|c|c|c|c|c|c|}
\hline \multirow[t]{3}{*}{ Variables } & \multicolumn{3}{|c|}{ Men } & \multicolumn{3}{|c|}{ Women } \\
\hline & Normal & Overweight & Obese & Normal & Overweight & Obese \\
\hline & $N=875$ & $N=1102$ & $N=415$ & $N=772$ & $N=893$ & $N=548$ \\
\hline \multicolumn{7}{|l|}{ Age } \\
\hline $60-64$ & 29.5 & $32.9^{\ddagger}$ & $39.3^{\S}$ & 29.0 & $39.0 \S$ & $40.1^{\S}$ \\
\hline $65-69$ & 25.1 & 28.2 & 31.8 & 25.9 & 28.3 & 24.6 \\
\hline $70-74$ & 20.1 & 18.6 & 16.4 & 19.6 & 15.9 & 17.7 \\
\hline $75-79$ & 14.3 & 12.4 & 8.7 & 12.6 & 9.5 & 9.5 \\
\hline$>80$ & 11.0 & 7.8 & 3.9 & 13.0 & 7.3 & 8.0 \\
\hline \multicolumn{7}{|c|}{ Marital Status } \\
\hline Unmarried & 25.1 & $20.9^{\#}$ & $18.3^{\ddagger}$ & 57.0 & 53.1 & 52.0 \\
\hline \multicolumn{7}{|c|}{ Educational level } \\
\hline$<$ primary & 66.2 & $59.3^{\ddagger}$ & 65.6 & 35.6 & $41.8^{\#}$ & 35.3 \\
\hline \multicolumn{7}{|c|}{ Self-rated economic status } \\
\hline Fair/poor & 82.0 & $76.3^{\ddagger}$ & 81.2 & 78.7 & 75.2 & 81.2 \\
\hline \multicolumn{7}{|c|}{ * Data expressed as percentages } \\
\hline \multicolumn{7}{|c|}{${ }^{\ddagger} p<.01$} \\
\hline \multicolumn{7}{|l|}{$\S p<.001$} \\
\hline$\# p<.05$ & & & & & & \\
\hline
\end{tabular}


lower prevalence of overweight. In subjects classified as overweight, there were fewer men who self-rated their socioeconomic status as poor.

Table II shows health characteristics stratified by gender in subjects with normal weight, overweight and obesity. In women, a self-rated health status of poor and arthritis were associated with obesity. Hypertension, diabetes mellitus, comorbidity, and long-distance walk limitation were more frequent in subjects classified as obese compared with normal. In men, there was a higher occurrence of myocardial infarction and a lower occurrence of bowel disease associated with overweight. Current smokers had a statistically significant lower prevalence of obesity and overweight in both genders. Alcohol consumption was associated with risk of overweight.

Results from logistic regression analysis, with adjusted odds ratio for the relationship between studied variables and overweight or obesity, are presented in Table III. Overall, women were more likely than men to be obese(OR 1.47). Lower educational level was significantly associated with lower risk of overweight (among men and women, OR 0.80 and 0.67 , respectively). Among men, poor economic self-perception and bowel disease were inversely associated with overweight and obesity, respectively. In the total population, obesity was associated with a higher risk of myocardial infarction (OR 1.61), but in the analysis stratified by gender there was no significant association. In both men and women, obesity was more common between subjects with hypertension (OR 1.38 and 1.71, respectively) and long-distance walk limitation (physically inactive) (OR 2.08 and 2.21, respectively). Age and tobacco use were inversely associated with obesity in men (OR 0.50 and 0.61 , respectively) and with overweight in women (OR 0.76 and 0.66 , respectively). The other variables were not significantly associated with the risk of overweight or obesity.

\section{Conclusion}

The prevalence of obesity and overweight according to age and gender found in the present study was similar to that which was found in the Mexican National Health Survey, in which the occurrence of obesity starts to decline from the 60 to 69 years age group to the age group 80 years and older, probably caused by population sur-

Table II

Health Characteristics in the OVERWEight and obese populations compared With the normal population. Mexican Health and Aging Study 200 **

\begin{tabular}{|c|c|c|c|c|c|c|}
\hline \multirow[t]{3}{*}{ Variables } & \multicolumn{3}{|c|}{ Men } & \multicolumn{3}{|c|}{ Women } \\
\hline & Normal & Overweight & Obese & Normal & Overweight & Obese \\
\hline & $N=875$ & $N=1102$ & $N=415$ & $N=772$ & $N=893$ & $N=548$ \\
\hline \multicolumn{7}{|l|}{ Self-rated health status } \\
\hline Poor & 60.2 & 59.1 & 65.4 & 66.9 & 68.2 & $74.7^{\ddagger}$ \\
\hline Hypertension & 30.6 & $37.4^{\ddagger}$ & $44.1 \S$ & 43.8 & $49.9^{\#}$ & $63.1^{\S}$ \\
\hline Diabetes Mellitus type 2 & 15.2 & 17.3 & 17.2 & 18.9 & 20.3 & 22.8 \\
\hline Myocardial infarction & 5.1 & 6.1 & $9.6^{\ddagger}$ & 4.1 & 2.6 & 4.6 \\
\hline Stroke & 3.8 & 3.9 & 3.7 & 4.5 & $2.0^{\ddagger}$ & 3.3 \\
\hline Arthritis & 17.7 & 19.8 & 21.0 & 21.8 & 30.9 & $34.9^{\ddagger}$ \\
\hline Bowel disease & 19.0 & 15.8 & $11.7^{\ddagger}$ & 23.1 & 20.7 & 22.0 \\
\hline Comorbidity & 24.0 & $28.7^{\#}$ & $29.6^{\#}$ & 37.0 & 37.6 & $49.1 \S$ \\
\hline Long-distance walk limitation & 21.1 & 24.6 & $32.4^{\S}$ & 30.0 & 30.6 & $47.4^{\S}$ \\
\hline \multicolumn{7}{|l|}{ Alcohol use } \\
\hline Abstainer & 59.0 & 54.9 & 57.6 & 87.0 & 83.9 & 84.5 \\
\hline Infrequent & 20.3 & 23.0 & 20.0 & 10.0 & 12.1 & 12.0 \\
\hline Moderate & 17.4 & 18.4 & 17.6 & 3.0 & 4.0 & 3.5 \\
\hline Heavy & 3.3 & 3.7 & 4.6 & - & - & - \\
\hline Current smoker & 38.7 & $31.4^{\ddagger}$ & $24 . I^{\S}$ & 38.5 & $27.0^{\#}$ & $27.5^{\#}$ \\
\hline \multicolumn{7}{|l|}{ * Data expressed as percentages } \\
\hline \multicolumn{7}{|l|}{$\neq p<.01$} \\
\hline \multicolumn{7}{|l|}{$\S p<.001$} \\
\hline$\# p<.05$ & & & & & & \\
\hline
\end{tabular}


Table III

Logistic Regression analyses of OVerWeight and obesity With ASSOciated Variables. Mexican Health AND Aging StudY 200I

\begin{tabular}{|c|c|c|c|c|c|c|}
\hline \multirow[t]{2}{*}{ Variables } & \multicolumn{2}{|c|}{$\begin{array}{c}\text { Total } \\
\text { OR }(95 \% \mathrm{Cl})\end{array}$} & \multicolumn{2}{|c|}{$\begin{array}{c}\text { Men }(N=2392) \\
\text { OR }(95 \% C l)\end{array}$} & \multicolumn{2}{|c|}{$\begin{array}{c}\text { Women }(22 \text { I3) } \\
\text { OR }(95 \% \mathrm{Cl})\end{array}$} \\
\hline & Overweight & Obesity & Overweight & Obesity & Overweight & Obesity \\
\hline \multicolumn{7}{|l|}{ Gender } \\
\hline Women & & $1.47(1.15-1.88)^{*}$ & & & & \\
\hline Age (years) & & $0.66(0.55-0.8 I)^{\ddagger}$ & & $0.50(0.39-0.64)^{\ddagger}$ & $0.76(0.58-0.99)^{\S}$ & \\
\hline \multicolumn{7}{|l|}{ Educational level } \\
\hline$<$ primary & $0.8 \mathrm{I}(0.67-0.97)^{\S}$ & & $0.80(0.64-0.99)^{\S}$ & & $0.67(0.48-0.95)^{\S}$ & \\
\hline \multicolumn{7}{|l|}{ Self-rated economic status } \\
\hline Fair/poor & $0.70(0.55-0.87)^{*}$ & & $0.69(0.53-0.91)^{*}$ & & & \\
\hline Hypertension & & $1.45(\mathrm{I} .5-\mathrm{I} .84)^{*}$ & & $1.38(1.04-1.83)^{\S}$ & & I.7I $(1.14-2.58)^{\S}$ \\
\hline Myocardial infarction & & $1.6 \mathrm{I}(1.05-2.47)^{\S}$ & & & & \\
\hline Bowel disease & & & & $0.47(0.31-0.72)^{\ddagger}$ & & \\
\hline Long-distance walk limitation & & $1.94(1.52-2.47)^{\ddagger}$ & & $2.08(1.53-2.82)^{\ddagger}$ & & $2.21(1.47-3.32)^{\ddagger}$ \\
\hline Currently smokes & & $0.72(0.56-0.94)^{\S}$ & & $0.61(0.44-0.84)^{*}$ & $0.66(0.46-0.97)^{\S}$ & \\
\hline \multicolumn{7}{|l|}{${ }^{*} p<.01$} \\
\hline \multicolumn{7}{|l|}{$\neq p<.001$} \\
\hline$\S p<.05$ & & & & & & \\
\hline
\end{tabular}

veillance. In men 60 to 69 years old, obesity was found in $24.4 \%$ of the men, in the 70 to 79 years age group it was $16.5 \%$, and in the age group 80 years and older, $10.7 \%$. In comparison, in women ages 60 to 69 obesity was $36.5 \%$, in the 70 to 79 years age group it was $27.9 \%$, and in the age group 80 years and older, $17.3 \% .{ }^{13}$

In this study, it was found that a lower educational level was associated with a lower prevalence of overweight in women and men, and a poor self-rated socioeconomic status in men. This is in concordance with Stunkard, ${ }^{16}$ who stated that in developing countries, people from lower educational levels and with a lower socioeconomic status may have difficulties getting access to sufficient food in order to become fat. On the other hand, in developed countries, people with a lower socioeconomic status have a higher prevalence of overweight and obesity because they have access to food but less knowledge about nutrition and poor physical activity.

It is important to take into account the great differences that exist in the health and nutrition of the Mexican population. People who live in cities generally present similar characteristics to those in developed countries (a greater prevalence of obesity and a tendency to be sedentary), and those living in rural areas tend to be thinner, their alimentation is mainly based on grains and vegetables and they have greater physical activity.

On the other hand, in the present study, the economic situation was defined based on self-perception and not on investigating the actual situation based on a set of socioeconomic variables. Therefore, the comprehensive investigation of the relation between socioeconomic conditions and obesity is considered to be important.

Hypertension and long-distance walk limitation were independently associated with obesity in men and women. These results are consistent with several studies that show that high BMI (past or current) is associated with a greater risk of self-reported functional limitation (especially mobility) among older persons. Subjects with a BMI ranking between 23 and 27 had about three times less chance of being ADL dependent in five years. ${ }^{20}$ Risk of loss of mobility is significantly associated with high BMI (>80th percentile) compared with moderate (21st-80th percentiles) BMI. ${ }^{21}$ Several studies have also shown that BMI and fat mass are positively related to disability, limitation in activities of daily living, walking upstairs, walking on flat surfaces, pulmonary disease, diabetes, and arthritis. ${ }^{22}$

In men, we found that smoking was inversely related to obesity, which is in accordance with Garrison et al. 1983 who state that smoking is clearly related to body size: lean individuals are more likely to be smokers than are those of normal or excess weight. ${ }^{23}$ Cigarette smoking appears to reduce body fat in a number of ways, including a reduction in caloric intake and an increased level of energy expenditure. Smoking cessation 
is also related to body size. Studies of mortality generally found that current smokers are leaner and have higher mortality than nonsmokers or past smokers.

Diabetes and arthritis-two diseases most commonly associated with excess weight-were not significantly associated with overweight or obesity. These results could be explained because subjects who are prone to the complications of overweight and obesity may have already died, leaving those who are more resistant to its effects. ${ }^{24}$

In this study, we found an effect of obesity on myocardial infarction in the total population, but this effect disappears in the gender-stratified analysis. The evidence of the effect of overweight and obesity in the incidence of cardiovascular disease is contradictory in some cases or not consistent in the literature. ${ }^{25}$

Data from weight and height were obtained from self-reports and could be underestimated or overestimated, especially in people 75 years and older; in the literature, however, we found that several studies have consistent findings of high correlations of self-reported height and weight with measured height and weight. ${ }^{26}$

Another aspect to consider about self-reporting is that people with a low educational level and or with cognitive decline would be underestimated.

In addition, measuring height and weight in older adults, taking into account their physical (scoliosis, lordosis, arthritis, amputations) and functional conditions (balance problems, walking limitations, dementias, prostrated condition), represents a problem.

In conclusion, some evidence was found of an association between overweight and obesity and some common health and sociodemographic conditions in the elderly; however, it is important to conduct longitudinal studies in order to discover the effect of BMI and other nutritional status indicators, such as body composition, on this population health group. This information can be useful for nutritionists and physicians who work with elderly people, in terms of making decisions as to whether or not to recommend losing weight.

\section{References}

I. Inelmen EM, Sergi G, Coin A, Miotto F, Peruzza S, Enzi G. Can obesity be a risk factor in elderly people? Obes Rev 2003;4: I47-155.

2. Sezginsoy B, Ross K, Wright JE, Bernard MA. Obesity in the elderly: survival of the fit or fat.J Okla State Med Assoc 2004;97(10):437-439. 3.Wannamethee S, Gerald-Shaper A, Whincup PH,Walter M. Overweight and obesity and the burden of disease and disability in elderly men. Int J Obes 2004;28(II):I374-I382.

4. Lerman IG,Villa AR, Martínez CL, Cervantes L,Aguilar CA, Wong B, et al. The prevalence of diabetes and associated coronary risk factors in urban and rural older Mexican populations.J Am Geriatr Soc 1998;46(I I):I387-I396.
5. National Institutes of Health, National Heart, Lung, and Blood Institute; $\mathrm{NHLBI}$ Obesity Education Initiative; and North American Association for the Study of Obesity. Identifying, evaluating, and treatment overweight in adults. Pan Am J Public Health 200 I; I0(2): I I 8- 22.

6. Stunkard A, Faith M,Allison K. Depression and obesity. Bio Psychiatry 2003;54(3):330-337.

7. Blazer D, Moody-Ayers S, Craft-Morgan J, Burchett B. Depression in diabetes and obesity.J of Psychosom Res 2002;53(4):913-916.

8. Zoico E, Di Francesco V, Guralnik JM, Mazzali G, Bortolani A, Guariento $S$, et al. Physical disability and muscular strength in relation to obesity and different body composition indexes in a sample of healthy elderly women. Int J Obes 2004;28(2):234-24I.

9. Heiat A, Vaccarino V, Krumholz M.An Evidence-Based Assessment of Federal Guidelines for Overweight and Obesity as they Apply to Elderly Persons. Arch Intern Med 2001;161:1 194-1203.

10. Himes CL. Obesity, disease, and functional limitation in later life. Demography 2000;37:73-82.

I I.American Obesity Association. AOA Fact Sheets. Available on: http:// www.obesity.org/subs/factfacts/obesity_global_epidemic.shtml 12. Kaplan MS, Huguet N, Newsom JT, McFarland BH, Lindsay J. Prevalence and correlates of overweight and obesity among older adults: findings from the Canadian national population health surveys.J Gerontol 2003;58A:1018-1030.

13. Olais G, Rojas R, Barquera S, Shamah T,Aguilar C, Cravioto P, et al. Encuesta Nacional de Salud 2000. Tomo 2, La salud de los adultos. Cuernavaca, Morelos, México: Instituto Nacional de Salud Pública, 2003. 14. Perissinotto E, Pisent C, Sergi G, Grigoletto F. ILSA Working Group. Anthropometric measurements in the elderly: age and gender differences. $\mathrm{Br}$ J Nutr 2002;87(2): 177-186.

15. Gutiérrez-Fisac JL, Lópéz E, Banegas J, Graciani A, Rodríguez F. Prevalence of Overweight and Obesity in Elderly People in Spain. Obes Res 2004;12(4):710-714.

16. Stunkard AJ. Factors in obesity: current views. In: Peña M. Bacallao J, eds. Obesity and Poverty: A New Public Health Challenge. Scientific Publication 576. Washington DC: Pan American Health Organization/ World Health Organization, 2000: 23-28.

17. University of Pennsylvania, University of Maryland, University of Wisconsin (USA), Instituto Nacional de Estadística, Geografía e Informática (Mexico). Estudio Nacional sobre Salud y Envejecimiento en México 200I. Available on: http://WWW.ssc.upenn.edu

18. Avila-Funes JA, Gutiérrez-Robledo LM, Ponce de León-Rosales S. Validity of heigh and weight self-report in Mexican adults: results from the National Health and Aging Study.J Nutr Health Aging 2004;8(5):355-36l.

19. World Health Organization. Physical status: the use and interpretation of anthropometry. Geneva:WHO, 1995.

20. Galanos AN, Pieper CF, Cornoni-Huntley JC, Bales CW, Fillenbaum GG. Nutrition and function: is there a relationship between body mass index and functional capabilities of community-dwelling elderly? J Am Geriatr Soc 1994;42:368-373.

21. Deschamps V,Astier X, Ferry M, Rainfray M, Emeriau JP, BarbergerGateau P. Nutritional status of healthy elderly persons living in Dordogne, France, and relation with mortality and cognitive or functional decline. Eur J Clin Nutr 2002;56:305-312.

22. Jensen $G L$, Rogers J, Obesity in older persons. J Am Diet Assoc 1998;98: |308-|3|I.

23. LaCroix AZ, Guralnik JM, Berkman LF,Wallace RB, Satterfield S. Maintaining mobility in late life. II Smoking, alcohol consumption, physical activity and body mass index. Am J Epidemiol 1993;137:858-1869. 24. Marinos E. Obesity in the Elderly. Obes Res 200I;9(4):S244-S248. 25. Garrison RJ, Feinleib M, Castelli WP, McNamara PM. Cigarette smoking as a confounder of the relationship between relative weight and long-term mortality. The Framingham Heart Study. JAMA 1983;249(16):2199-2203. 26. Rowland M. Self-reported weight and height. Am J Clin Nutr 1990;52: I I25-II33. 